\title{
Influence of storage under unfavourable conditions on the caking properties and fungal contamination of potato starch and wheat flour
}

\author{
Justyna Wajs®, Maciej Bańda®, Jacek Panek®, Agnieszka Nawrocka®, Magdalena Frac®®, \\ and Mateusz Stasiak*i) \\ Institute of Agrophysics, Polish Academy of Sciences, Doświadczalna 4, 20-290 Lublin, Poland
}

Received January 20, 2020; accepted February 24, 2020

\begin{abstract}
In recent years, there has been growing interest in the elimination of undesirable phenomena in the processing of bulk materials. In this study, the relationship between the mechanical properties of caking, as analysed with FTIR structural measurements, and the phenomena connected with fungal growth were investigated in wheat flour and potato starch. The materials were stored in high humidity conditions at room temperature $\left(20 \pm 2^{\circ} \mathrm{C}\right)$ in order to rapidly cause caking. The results showed changes in cake strength, for which the maximum force recorded by the sensor during storage was assumed. For the potato starch, the maximum strength occurred on the 8th day of storage and amounted to $29.4 \mathrm{~N}$. From that day, the level of strength in this powder started to decrease, however, an increase in fungal contamination was also observed. Day 8 also marked the beginning of structural changes in the potato starch, which were observed in the FTIR spectra. The results obtained suggest that the strength of the agglomerates correlates with structural changes and fungal contamination.
\end{abstract}

Keywords: caking, food powders, mechanical properties, fungal spoilage, powder quality

\section{INTRODUCTION}

Powdered ingredients play a very important role in many branches of the food industry. Powdered materials are easier to transport, store, weigh and process (Bröckel et al., 2006; Cuq et al., 2011; Freeman et al., 2015). However, at each of the production stages, problems may occur that hinder the correct production process, which may in turn cause changes in the physical parameters of the material, and can lead to changes in its structure and chemical com-

*Corresponding author e-mail: m.stasiak@ipan.lublin.pl position. Any change to the material properties of powders during processing may be associated with the risk of undesirable features that lower the quality of the raw materials.

One of the unfavourable characteristics that develop during the processing of bulk powder is caking (Bröckel et al., 2006; Freeman et al., 2015). The phenomenon of caking occurs when a free-flowing powder begins to form larger agglomerates (Zafar et al., 2017). The presence of agglomerates in the final product is associated with a deterioration in its favourable sensory properties. It is also possible that a reduction may occur in the solubility of the material along with an increase in the enzymatic activity and lipid oxidation (Chung et al., 2003). For the consumer, clumped powder is a sign of poor product quality and may be associated with an increased risk of microbiological contamination. The presence of agglomerates (Chung et al., 2003) and increased air humidity promote the development of pathogenic bacteria and fungi in bulk food materials (Pereira and Sant'Ana, 2018).

The occurrence of caking is influenced by the internal characteristics of the bulk material such as particle size, cohesion and the content of amorphous structures, as well as external factors. External factors include temperature, ambient humidity, and external load (Zafar et al., 2017). Due to their physicochemical nature, food powders are sensitive to changes in temperature and water content. Therefore, at constant temperatures, humidity plays a major role in caking (Wang et al., 2017). Agglomeration is

(C) 2020 Institute of Agrophysics, Polish Academy of Sciences 
developed via the formation of intramolecular and intermolecular bonds facilitated by absorbed water, making the powder grains viscous and leading to larger agglomerations (Chung et al., 2000).

For food powders, the most frequently described parameters are particle size, density and flow (Cuq et al., 2011), which may be determined using a Powder Characteristics Tester (PT-S, Hosokawa) (Carr, 1965). Investigations of food powders should be extended to include a parameter related to the identification and estimation of the powder caking level. The currently proposed agglomeration indexes are based on the mechanical properties of the powder (e.g., force displacement test, penetration test, shear test), particle morphology based on microscopic image analysis (e.g., aspect ratio, sphericity, bluntness), and statistical analysis (Carpin et al., 2016; Chen et al., 2018; Zafar et al., 2017). A significant part of the research conducted to describe caking in the literature was designed to determine parameters related to the flowability and strength of the powder. There are many methods used to test the strength of powders. Fitzpatrick et al. (2017) used an indenter to describe the phenomenon of caking, by means of which the strength of the agglomerates was determined. In a study by Descamps et al. (2013), a ring shear test was used to describe the strength of agglomerates. Research experience with agglomerates is generating new methods of measurement, such as the study of flow changes during the formation of agglomerates (Freeman et al., 2015) or the modification of the existing methods of measurement of other parameters. Investigations related to structural changes and the process of creating crystalline bridges are important elements in the process of learning about the mechanisms of agglomerate formation. For this purpose, it is worth using modern techniques to determine changes in the structure, such as Fourier transform infrared spectroscopy (FTIR), nuclear magnetic resonance (NMR), and Raman spectroscopy, which may contribute to a deeper understanding of the phenomenon of caking (Chen et al., 2018).

The purpose of this work was to search for the relationships between the mechanical properties of agglomerates during their formation and the structural changes occurring in the particles of the material during storage. The work focuses on the caking process for two different materials. The current literature abounds with publications regarding agglomerates and their formation in various humidity conditions. This study aimed to generate the agglomerate as rapidly as possible with the aid of a high level of humidity. In addition, high humidity conditions are very favourable for the growth of microorganisms. These research conditions make it possible to assess the period of time in which the bulk material can still be used in the event of a breakdown in the normal transport and warehousing system. This study aims to observe the correlation between the occurrence of microorganisms and the phenomenon of caking. An attempt was made to characterize the role of microorganisms in the process of creating agglomerates. It was also designed to determine whether there is a real causal relationship between caking and the number of emerging microorganisms. Strength measurements and spectrophotometric measurements of changes in the characteristics of powder during storage were carried out, these constitute a novel approach to assessing the phenomenon of caking. From the literature review, it was determined that no other studies have described changes in the formation of agglomerates during wheat flour and potato starch storage, and there are no literature data linking mechanical tests with microbial activity and FTIR measurements.

\section{MATERIALS AND METHODS}

Potato starch (PPZ Trzemeszno, Poland) and wheat flour type 500 (Młyn Szczepanki, Łasin, Poland) were used as the research materials. The powders were dried in a SUP30 laboratory dryer (Wamed, Warsaw, Poland) until their moisture content was $3 \% \pm 0.5$. The process of drying the powders to achieve the aforementioned humidity level was aimed at unifying the water content of the samples, so that in each sample the initial water content was at the same low level. A batch of each of the materials was passed through a sieve to create a more homogeneous system. Measuring vessels (perforated cylinders) were completely filled with the sieved material -100 vessels were filled with powder, each vessel constituted a separate sample. The net weight of each sample filled with powder was $6 \mathrm{~g}$.

Prepared samples were placed in a desiccator with increased air humidity, which was provided by distilled water at the bottom of the desiccator. Storing powder samples under such humidity conditions aimed to induce a rapid caking process. The material was stored under high air humidity conditions and room temperature $\left(20 \pm 2^{\circ} \mathrm{C}\right)$ until mould hyphae growth on the surface of the powder was observed. The potato starch was tested on days 2, 4, 8, 10, 17 , and 24, while measurements of wheat flour were taken on days 2,4 , and 8 due to the rapid appearance of mould on the material. In order to maintain natural storage conditions, sterilization was not performed. The control sample for each analysis consisted of three powder samples that were dried but not stored. The results were averaged and the control sample was recorded on the charts as day 0 . The storage time periods for potato starch and wheat flour were terminated when mould began to appear, this occurred on day 24 and day 8, respectively.

A Mettler Toledo HG63 automatic moisture analyser (Laboratory and Weighing Technologies, Greifensee, Switzerland) was used to measure the moisture content. The instrument carries out measurements based on the thermogravimetric principle. The moisture content is determined on the basis of the weight loss which occurs due to the drying (by heating) of the sample. The measurements 
were carried out in triplicate for each test at $105^{\circ} \mathrm{C}$ until the measuring device stopped, which meant that no further weight loss had occurred.

In the next stage, an experiment was carried out to determine the strength of the agglomerates being formed in the ensuing days of storage at high humidity. Penetration force measurements were carried out in cylindrical perforated vessels with a diameter of $24 \mathrm{~mm}$, a height of $30 \mathrm{~mm}$ and a mesh diameter of $1.5 \mathrm{~mm}$ in order to maximally increase the surface area of the material open to moisture access. An indenter was applied in the study, which was similar to that used by Fitzpatrick et al. (2017). A universal testing machine (Instron, Norwood, USA) was used to measure the force required for penetration. A cylindrical penetrometer ( $5 \mathrm{~mm}$ diameter, $14 \mathrm{~mm}$ long) was used, which moved at a constant speed of $30 \mathrm{~mm} \mathrm{~min}^{-1}$ until it reached a depth of $14 \mathrm{~mm}$ (Fig. 1). The largest force registered by the sensor was adopted as the cake strength (Fitzpatrick et al., 2010). For each storage day selected for the analysis, a strength measurement was carried out for the three samples, the average of which produced the final result.

A Nicolet 6700 FTIR spectrometer (Thermo Scientific, USA) was used for spectrophotometric measurements. Spectra were recorded in the range of $400-4000 \mathrm{~cm}^{-1}$ with 128 combined scans. Each measurement was performed in five repetitions, and the spectra were averaged. Baseline correction and further analysis were performed using OMNIC software.

In order to determine the structural changes in the powders studied, difference spectra in the spectral regions of 900-1 800 and 2400-3800 $\mathrm{cm}^{-1}$ were calculated according to Nawrocka et al. (2018). Briefly, all spectra were band area-normalized, and then the spectrum of the control sample was subtracted from the spectra of the moisturized samples.

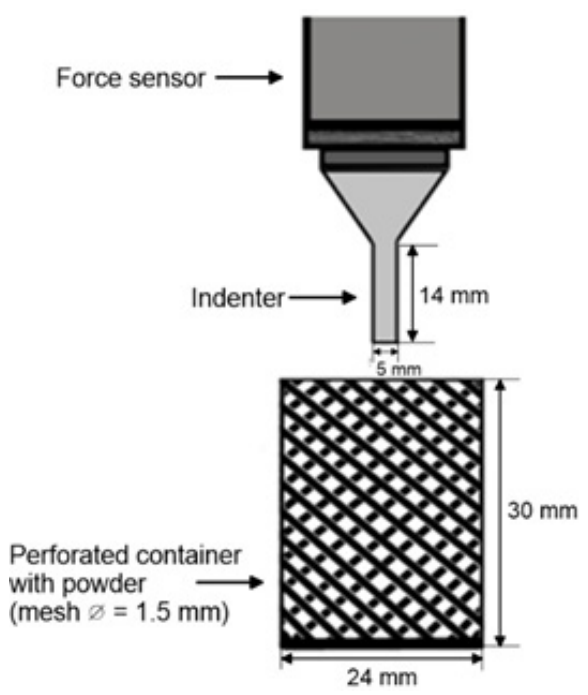

Fig. 1. Diagram of the measurement of cake strength.
On the basis of the FTIR spectra, a crystallinity index analysis of the examined materials was also performed. The crystallinity index (CI) was defined as the intensity ratio of the bands at 1022 and $1000 \mathrm{~cm}^{-1}(\mathrm{CI}=\mathrm{I}(1022) / \mathrm{I}(1000))$ (Warren et al., 2016).

The assessment of mould growth within the material after a certain number of days of storage $(2,4,8,10,17$, 24) at $25^{\circ} \mathrm{C}$ was performed according to the protocol of ISO 21527:2009. In this method the stored powder samples were homogenised (Biocorp, Warsaw, Poland), diluted 10 -fold in sterile distilled water, and mixed thoroughly. Serial dilutions were prepared, and dilutions of $10^{-2}$ and $10^{-3}$ were selected for the analyses. Sterile Potato Dextrose Agar - PDA (BioMaxima, Lublin, Poland) on a Petri dish was inoculated with a $100 \mu$ l suspension of the diluted material. The spread-plate technique was used, and the inoculum was spread with a sterile plastic L-shaped spreader onto a solid PDA medium that supports fungal growth. The plates were then incubated according to the recommendations of the standard method at $25^{\circ} \mathrm{C}$ for 7 days. Colonies were counted after 2, 5 and 7 days of incubation and then converted to colony forming units (CFU) per gram of dry matter $\left(\mathrm{CFU} \mathrm{g}{ }^{-1}\right)$. The analysis for each selected day were made in triplicate.

\section{RESULTS AND DISCUSSION}

In the first step, the caking force of the samples was measured. The potato starch and wheat flour were placed in perforated vessels (Fig. 2), which made it possible to evenly moisten the powder and thus to obtain model agglomerates.

The aim of the measurements was to determine the changes in agglomerate strength depending on the storage time in high humidity. On the basis of the obtained results, the average maximum cake strength was determined over the course of the storage period, which is presented in Fig. 3.

The potato starch and wheat flour samples from day 0 , which was a control sample are characterized by a very low cake strength value of 0.22 and $0.05 \mathrm{~N}$, respectively. Additionally, for both of these materials, a rapid increase in agglomerate strength was found. In the case of the wheat flour, the cake strength values for days 2,4 , and 8 were 0.61 , a

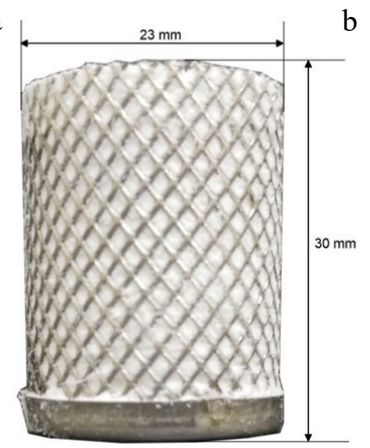

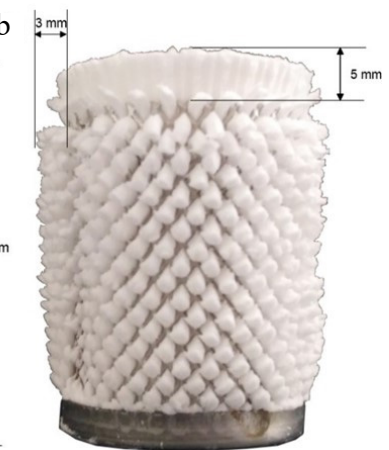

Fig. 2. Perforated potato starch containers: a - control sample, $\mathrm{b}$ - after 8 days of storage. 

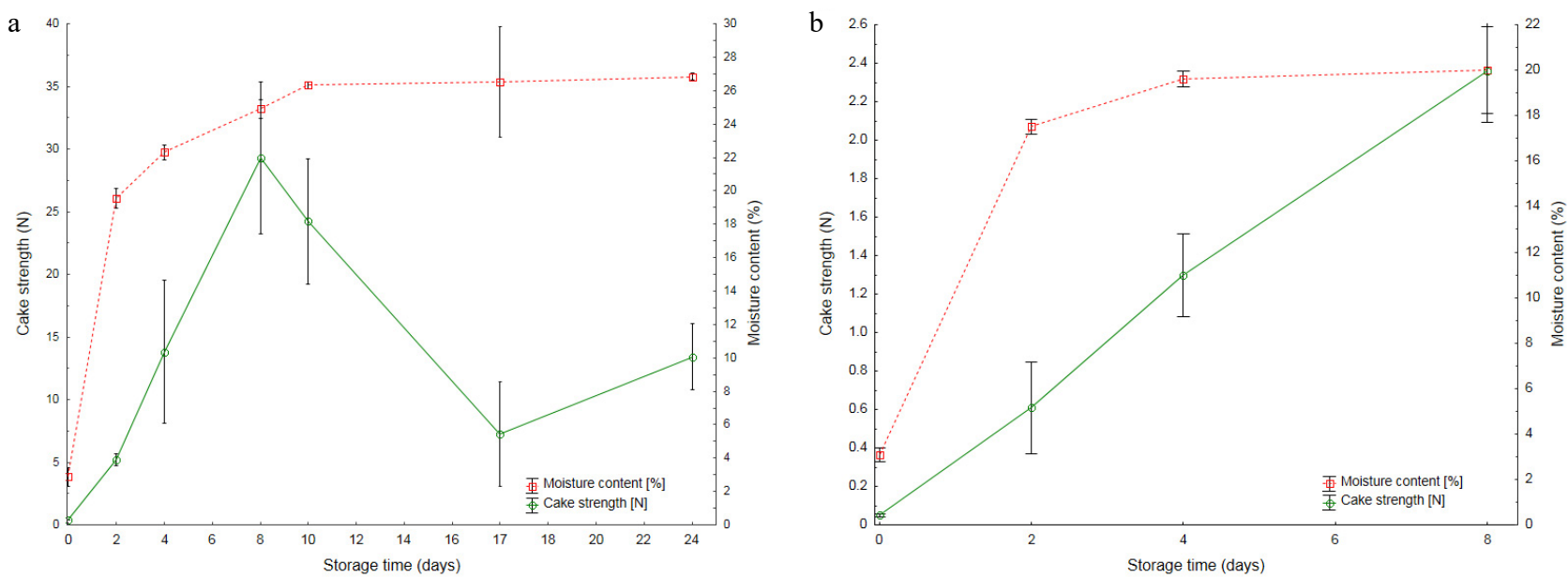

Fig. 3. Changes in the maximum cake strength and material moisture content over the storage period for: $a-$ potato starch and $b-$ wheat flour. Error bars represent the standard deviation.

1.31 , and $2.36 \mathrm{~N}$, respectively, which were significantly lower than those of potato starch on the same days (5.27, 13.78 , and $29.40 \mathrm{~N}$, respectively). On day 8 , the strength of the agglomerates was at its highest. After this time, no further increase in strength was observed. On day 10, the value of the cake strength started to decrease. Additionally, at the same time, the maximum absorption of ambient water took place. In the ensuing days of measurements, the moisture content of the material did not change, which may mean that all chemical groups that could bind water via hydrogen bonds were saturated. The absorbed water caused the powder material to swell and escape through the holes in the pot. Fitzpatrick et al. (2017) carried out similar strength tests for whey and maltodextrin permeate and "non-sticky" powders exposed to $76 \%$ moisture. In the case of this work, an increase in the strength of the agglomerates during storage in an environment with increased humidity was also observed. The authors suggest that the caking of the permeate is associated with the absorption of moisture by amorphous lactose, and a slight decrease in humidity may indicate its crystallization. Amorphous powder particles possess viscous properties, which contribute to changes in the structure, e.g., through the formation of intermolecular bridges (Descamps et al., 2013). Additionally, in a study of skimmed milk powder (Fitzpatrick et al., 2008), the strength of the powder increased in high humidity air. This means that agglomerates resulting from water absorption were also formed in this material. In addition, these agglomerates formed much faster at higher temperatures, suggesting that temperature also plays an important role in the formation of agglomerates.

In the case of wheat flour, due to the presence of mould, the maximum strength of the agglomerates could not be determined. On the other hand, as in the case of potato starch, the moisture content of the wheat flour increased rapidly during the first days of measurement. However, the moisture content of wheat flour stabilized much faster than that of potato starch, as early as day 4 and to a much lower maximum moisture level. Such a difference may result from the smaller number and lower availability of all these groups that can bind water through hydrogen bonds. In a study by Fitzpatrick et al. (2017), wheat flour was subjected to storage in ambient humidity $(76 \%)$. In this study, wheat flour reached a very low cake strength of $0.17 \mathrm{~N}$ and $12.8 \%$ moisture content on the 6th day of storage. In the presented experiment, both the cake strength and moisture content of the material were already higher on the 2nd day, which means that the ambient conditions affect the powder characteristics such as caking.

By analysing moisture dependence, one can observe that the powder material strength increases as the moisture content increases up to a point. This result was found for both potato starch and wheat flour in the present experiment. The relationship between moisture content and strength only existed up to day 8 (Fig. 3a) and day 4 (Fig. 3b). In the experiment of Fitzpatrick et al. (2010), maltodextrin and skimmed milk powder placed in 100\% moisture behaved similarly, however, the crystalline salt showed a different tendency. The increasing moisture content of the material only slightly increased the strength of the crystalline salt agglomerate (about 1 to $2 \mathrm{~N}$ ), and in addition, this increase only occurred in the first days of the measurements, because the strength decreased in the following days.

FTIR spectra were analysed in order to observe structural changes occurring during the process of potato starch and wheat flour agglomeration. The obtained difference spectra were divided into three ranges: 900-1 200, 1200-1 800, and $2400-3800 \mathrm{~cm}^{-1}$. As in the case of the measurement of the strength of caking, fungal contamination was observed on the 8th day for wheat flour and on the 24th day for potato starch.

In the range of $900-1200 \mathrm{~cm}^{-1}$, significant changes were observed in both wheat flour and potato starch (Fig. 4a, b). Differences in this range may indicate changes in structure, 
a

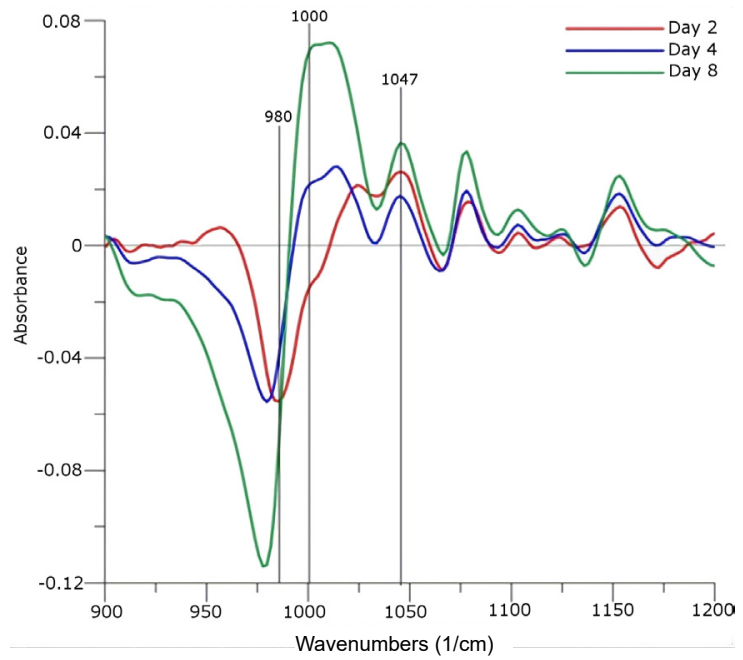

c

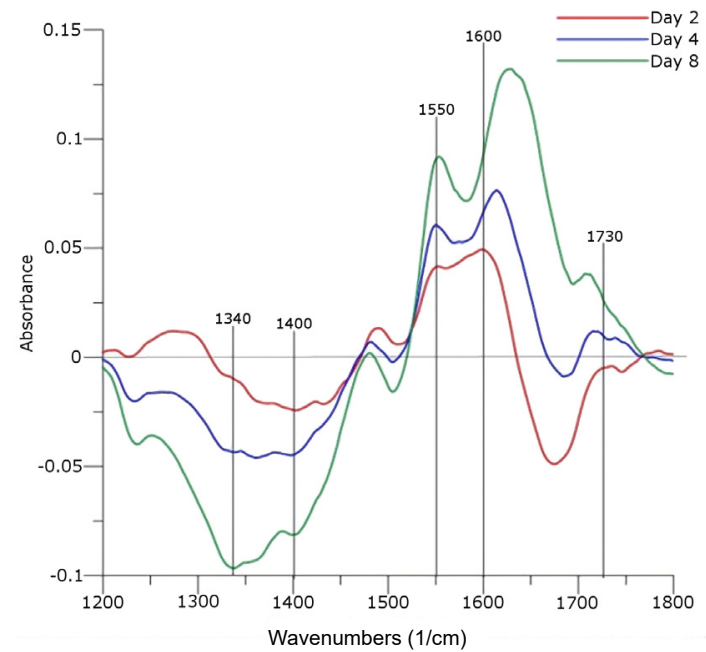

e

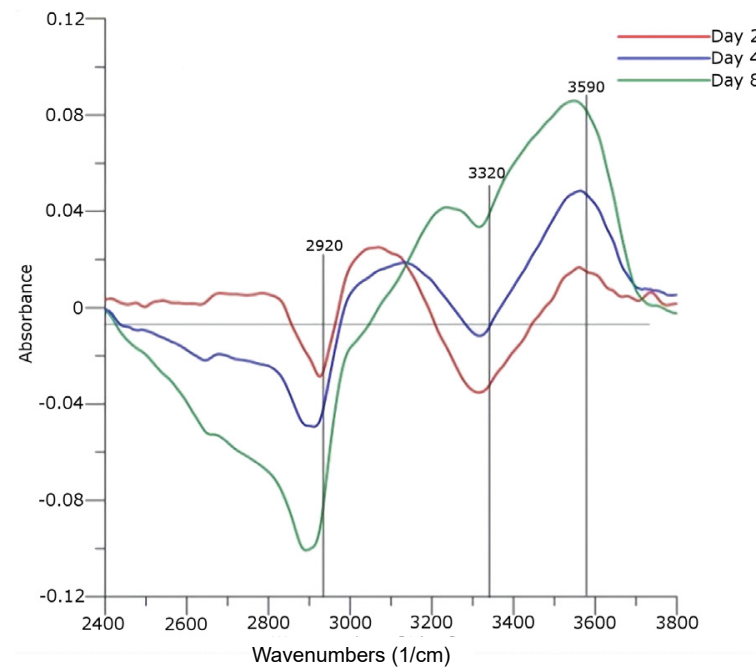

b

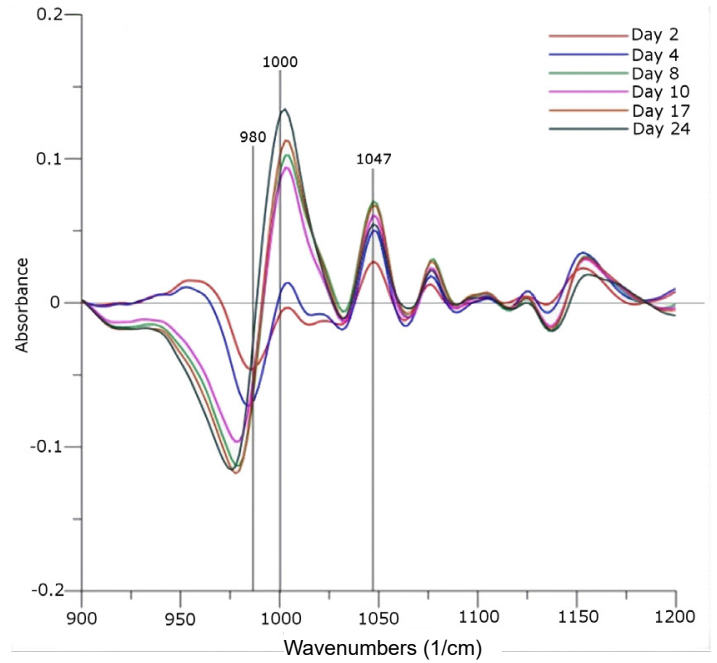

$\mathrm{d}$

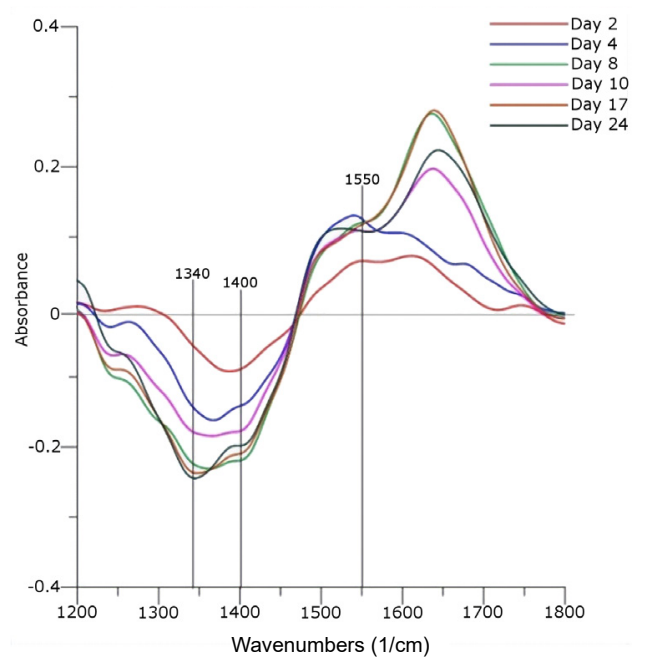

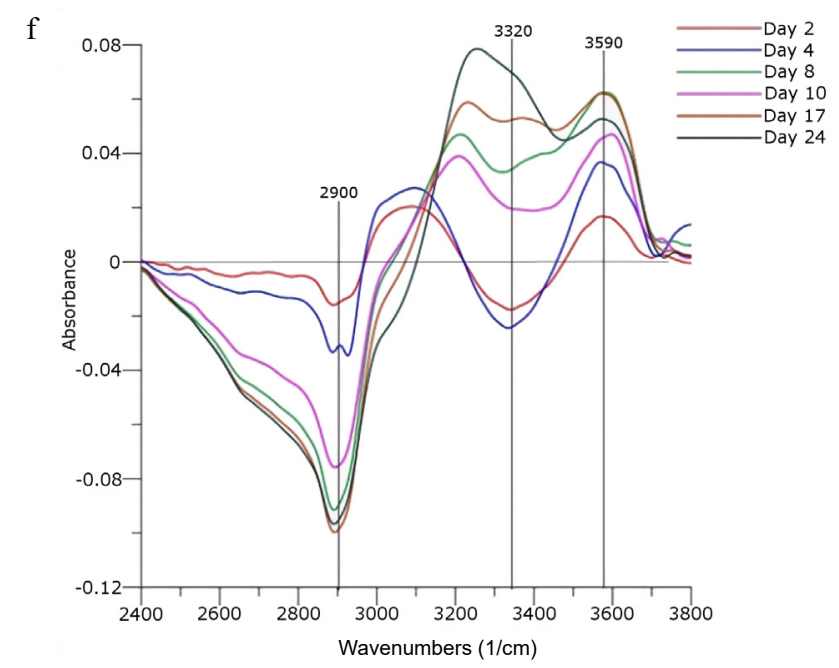

Fig. 4. Difference spectra of: a) $900-1200 \mathrm{~cm}^{-1}$ for wheat flour, b) $900-1200 \mathrm{~cm}^{-1}$ for potato starch, c) $1200-1800 \mathrm{~cm}^{-1}$ for wheat flour, d) $1200-1800 \mathrm{~cm}^{-1}$ for potato starch, e) $2400-3800 \mathrm{~cm}^{-1}$ for wheat flour, f) $2400-3800 \mathrm{~cm}^{-1}$ for potato starch. 
as the region of $400-1500 \mathrm{~cm}^{-1}$ is the fingerprint region of starch (Dankar et al., 2018). A significant change in the spectra of both powders was the reduction in band intensity at $980 \mathrm{~cm}^{-1}$. In potato starch, this decrease was gradual, while in wheat flour the band intensity was at a similar level on days 2 and 4, and on day 8 there was a sharp drop in intensity. In addition, this band shifted after subsequent days of storage. The shift of this band to $975 \mathrm{~cm}^{-1}$ in potato starch was observed only until the 8th day. No further peak changes were observed over the subsequent days of measurement. In wheat flour, there is also a shift in this band to $975 \mathrm{~cm}^{-1}$; however, due to the completion of measurements on day 8 , it is not clear whether this band undergoes further transformations. This band is characteristic for starch and is associated with the vibration of the $\mathrm{COH}$ groups, and the changes occurring in it may be the result of a reduction in the numbers of hydrogen bonds. A similar change in this same peak was observed in a study by Siemion et al. (2004). As a result of heating, the peak shifted to $1022 \mathrm{~cm}^{-1}$, which indicates that both heating and humidity affect the changes associated with the reorganization of the starch structure. A characteristic modification in the range of $900-1200 \mathrm{~cm}^{-1}$ is also an increase in peak intensity at $1047 \mathrm{~cm}^{-1}$ in wheat flour and potato starch. This peak can be related to the crystalline phase in starch grains; therefore, this value, together with the intensities of the peaks at 1000 and $1022 \mathrm{~cm}^{-1}$, is used to characterize amorphous and crystalline starch (Warren et al., 2016; Dankar et al., 2018). Important changes in the range of $900-1200 \mathrm{~cm}^{-1}$ are also the differences in the peak intensity of the peaks at 1000 and $1022 \mathrm{~cm}^{-1}$. These bands are most susceptible to changes in starch structure and show significant sensitivity to water (Warren et al., 2016). The peak at $1022 \mathrm{~cm}^{-1}$ in the spectra of wheat flour undergoes a shift and an additional increase in intensity. Potato starch is also characterized by an increase in the intensity of this band, but without a significant change in the wavelength. Warren et al. (2016) and Dankar et al. (2018) suggested that the $1022 \mathrm{~cm}^{-1}$ band is related to amorphous structural changes in starch. The exposure of native starch to changes in temperature, humidity or radiation may contribute to amorphous modifications in the form of changes in intensity in the spectral range of 1000-1022 $\mathrm{cm}^{-1}$. On the basis of the absorbance values of the bands at 1000,1022 and $1047 \mathrm{~cm}^{-1}$, it is possible to determine the orderly molecular structure of starch. Two indicators, the intensity ratios of the bands at 1022 to 1000 and 1047 to $1022 \mathrm{~cm}^{-1}$, were used for this purpose. For hydrated starches, the former ratio is more accurate and more frequently used, which, together with other techniques, may be a predictor of an ordered structure. The 1047 to $1022 \mathrm{~cm}^{-1}$ intensity ratio does not show a correlation with hydrated starches, but it is relevant to non-hydrated starches (Warren et al., 2016). The crystallinity index values were calculated for each powder material, and the results are presented in Fig. 5.

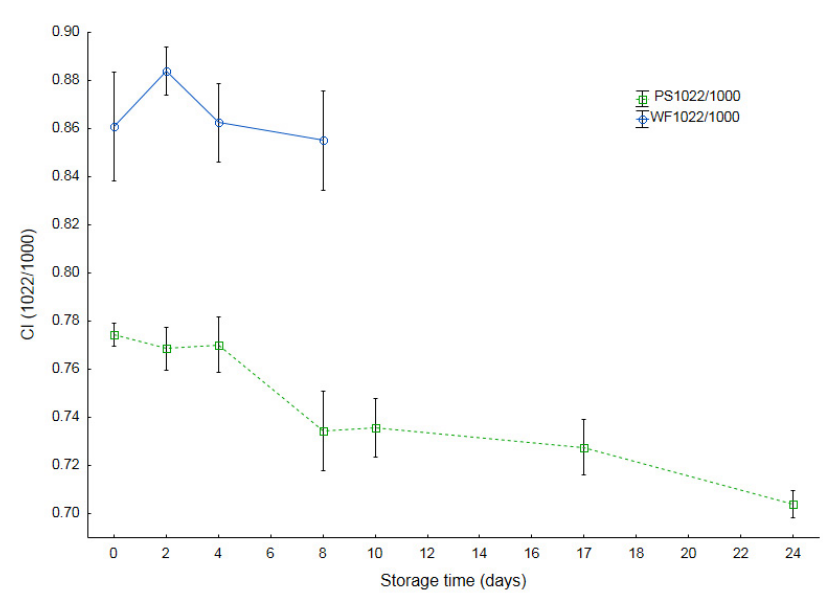

Fig. 5. Changes in the starch crystallinity index during storage in high humidity conditions. Error bars represent the standard deviation. PS1022/1000 - coefficient for potato starch; WF1022/1000 - coefficient for wheat flour.

The crystallinity index values were higher for wheat flour. The crystallinity index of wheat flour reached its maximum value on the second day, and after the next two days, it decreased. On day 8 , the value of the ratio of the intensities of the 1022 to the $1000 \mathrm{~cm}^{-1}$ bands increased marginally. Slight changes in the calculated ratio for wheat flour are probably due to a lower content of crystalline structures and the presence of additional ingredients such as proteins, vitamins and other components (Guo et al., 2018). Potato starch is characterized by a lower value of the crystallinity index. Until day 8, this value remains relatively constant, while it decreased in subsequent days. The reason for this decrease may be the gradual hydration and destruction of the crystalline phase of starch, which results in the reduction of its orderly structure. Structural changes occurring in the starch during these days were observed in the form of a clear delamination of the material, as well as the occurrence of the highest strength of the agglomerates. After 10 days of storage in high humidity, the crystallinity index continued to decrease. With the decrease in crystallinity after 10 days, a decrease in cake strength was also observed. Additionally, on day 10 , the material reached its maximum water saturation, which did not change in the ensuing days. On the basis of the obtained results, it was shown that caking and the moisture content also affects the crystalline fractions of the materials. Due to the short storage time of the experiment, it is not possible to accurately predict changes in the crystallinity index for wheat flour. The crystallinity index for potato starch decreased during the process of agglomerate formation. This decrease may indicate that the crystalline fraction of amylopectin, which represents a higher proportion than amylose in potato starch, was destabilized. The destruction of this structure may be caused by the swelling of amorphous structures, for which the water absorbed from the environment is responsible. The absorption of water by 
the material favours the swelling of the amorphous fraction, which causes disturbances and destabilization in the crystalline structure. These changes, in turn, may affect the agglomeration of the material (Zhu, 2018; Fitzpatrick et al., 2017; Warren et al., 2016).

In the spectral range of $1200-1800 \mathrm{~cm}^{-1}$, the most important changes were observed in the bands at 1340 , 1400,1550 and $1640 \mathrm{~cm}^{-1}$. These changes mainly concern the differences in the intensity of the marked peaks. During storage, the intensity of the $1400 \mathrm{~cm}^{-1}$ band decreased, which may be associated with the vibrations of the $-\mathrm{CH} 2$ and -COO groups. According to Dankar et al. (2018), the vibrations of these groups have been attributed to the $1412 \mathrm{~cm}^{-1}$ band, which, in addition to the bands at 1047 and $1022 \mathrm{~cm}^{-1}$, is also a characteristic starch band. The highest increase in absorbance values in wheat flour was observed for the peak at $1600 \mathrm{~cm}^{-1}$. Additionally, the maximum of this peak shifted from 1608 to $1635 \mathrm{~cm}^{-1}$ over 10 days. This shift was also present in the spectra of potato starch, but it was not as pronounced as was the case of wheat flour. These changes may be related to the hydration of gluten proteins observed in the amide II band (Nawrocka et al., 2017) or they may be related to the vibrations of the $\mathrm{C}=\mathrm{O}$ groups belonging to the starch. Dankar et al. (2018) and Dar et al. (2018) also observed changes in the $1640 \mathrm{~cm}^{-1}$ band in their studies. The reason for the changes in these groups is the presence of water, which is absorbed by amorphous regions (Dankar et al., 2018) and becomes attached to starch structures by hydrogen bonds (Dar et al., 2018). Wheat flour consists of approximately 75\% starch (Guo et al., 2018), and shifts were observed for both wheat flour and potato starch, suggesting that the changes in the $1640 \mathrm{~cm}^{-1}$ band correspond to the hydrogen-linked carbonyl groups of the starch. It should be noted that these shifts are unlikely to be the result of the hydration of gluten proteins because potato starch contains only $0.33 \%$ protein (Alvani et al., 2011).

In the spectral range of $2400-3800 \mathrm{~cm}^{-1}$, a $2920 \mathrm{~cm}^{-1}$ band was observed in wheat starch, the intensity of which decreased with storage time, and it also shifted to $2900 \mathrm{~cm}^{-1}$. In potato starch, this band also appeared at $2900 \mathrm{~cm}^{-1}$ and its intensity also decreased, but without an obvious shift. The intensity of this band decreased until day 8 , while in subsequent days, it remained relatively constant. Another significant change was the increase in the intensity of the $3200 \mathrm{~cm}^{-1}$ band for both potato and wheat starch. Dar et al. (2018) described similar changes at $3267 \mathrm{~cm}^{-1}$ in their experiment. Bashir and Aggarwal (2017) observed a very wide band at $3235 \mathrm{~cm}^{-1}$. They attributed this band to the stretching vibrations of $-\mathrm{OH}$ groups. An increase in the intensity of the band at $3550 \mathrm{~cm}^{-1}$ was also observed in the spectrum. This peak was also attributed to the vibrations of the $-\mathrm{OH}$ groups (Dankar et al. 2018). Warren et al. (2016) noted in their experiment that all irrigated starch samples were characterized by an increase in intensity and more pronounced peak values in the whole range of 3000 $3700 \mathrm{~cm}^{-1}$, which may suggest that changes in this area are significantly influenced by water content.

The last stage of the experiment was an analysis of fungal contaminants, which grew over the subsequent storage days. An increase in mould counts was observed in both materials. It was also observed that one type of fungus dominated in wheat flour and potato starch, and in potato starch after day 17, it may be that one genus inhibits the growth of other microorganisms. A similar observation was made by Berghofer et al. (2003) who studied wheat microflora and its grinding processes. The results presented in that study indicate the dominance of Aspergillus sp. and Penicillium sp. in flour.

The development of fungal contamination in the following days was shown in Fig. 6. No fungal growth was observed in the control samples as well as in the first days of storage of the samples of both materials. After the 8th day, the number of colonies increased rapidly in both materials. An increase in the amount of mould was observed much earlier in wheat flour, where colonies began to appear on the 4th day. The rapid growth of microorganisms on wheat flour was also observed by Abdullah et al. (2000). As was the case of the research presented, during periods of high relative humidity, they observed the appearance of fungi after approximately 8 days. The more rapid growth on this material is probably due to better conditions for development because in addition to wheat starch, wheat flour also contains proteins, vitamins and other components that microorganisms are able to assimilate more easily (Guo et al., 2018). An additional factor affecting the development of microbiological contamination may be the different amylose contents of the tested materials. Previous literature data showed that the amylose content was much lower in potato starch than in wheat starch (Buléon et al., 1998; Themeier et al.; 2005, Moorthy et al., 2006; Piecyk et al., 2009), which is one of the components of wheat flour. Arifin et al. (2014) showed that differentiation in the amount of amylose fractions may affect the growth rate of microorganisms. The presence of microorganisms depends primarily on the quality of the grain delivered for production. An important role is also played by the activities employed in its transportation and processing to form a final product, such as grinding. Sediments may accumulate in equipment during grinding, which leads to the presence of microorganisms in the final product (Berghofer et al., 2003). In addition to these factors, the growth of microorganisms in the stored material is affected by water activity, temperature, and the concentrations of oxygen and carbon dioxide. The development of microorganisms depends on the water activity in a given product (Sautour et al., 2002), especially in bulk products. 


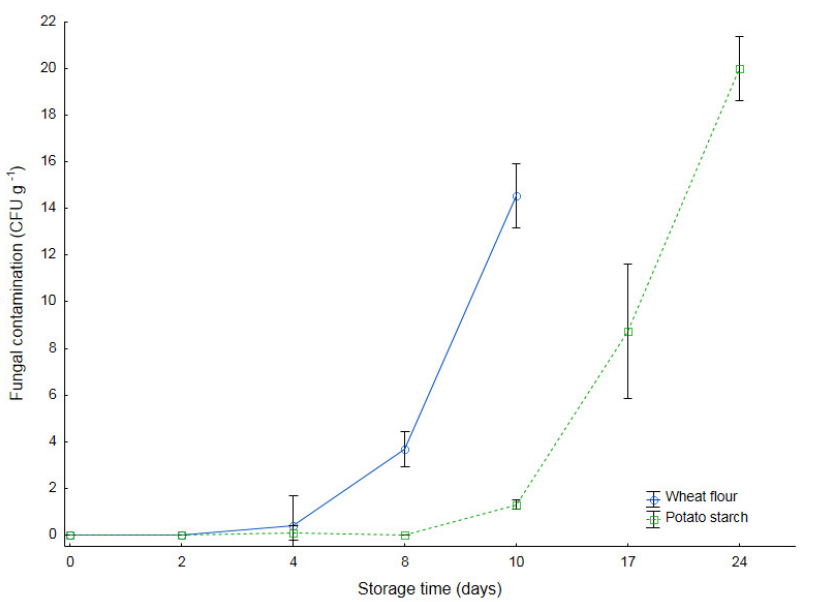

Fig. 6. Fungal contamination in potato starch and wheat flour after 5 days of incubation. Error bars represent the standard deviation.

Under storage conditions, the water activity is already at the critical level of 0.85 where it contributes to the growth of storage fungi (Mannaa and Kim, 2017).

In comparing the graphs of the caking force with the graph of fungal contamination in potato starch, it may be observed that when the growth of fungi starts, the caking force begins to decrease. This negative relationship suggests that the growth of mould can also affect the strength of the powdered material. Additionally, on day 8 , the starch crystallinity index drops. This decrease may be related to the breakdown of the crystal structure by the absorbed water, but the increasing number of fungi may also suggest that the microorganisms began to breakdown the starch as a nutrient medium. Another factor in the decrease in crystallinity may be the breakup of starch structures by the growing mycelium. The relationship between the strength of the powder and the increase in the number of fungi was difficult to determine in wheat flour. This strength may originate from the starch contained in the flour, whereas the initial growth of mould may be mainly due to other components that are contained in wheat flour. In the case of crystallinity, the situation was similar. There were no differences in the crystallinity measurements for wheat flour. These observations may mean that the starch that is contained in the wheat flour had not yet been used by fungi.

\section{CONCLUSIONS}

A study concerning agglomerate formation in wheat flour and potato starch during storage at elevated humidity levels is presented.

1. In the material agglomerated under the influence of moisture, changes in strength, and in structure take place, and the powder becomes a habitat for fungi.

2. As the moisture content of the samples increases up to a point of 25 and $20 \%$ respectively, the degree of caking increases. The absorption of ambient water also contributes to the strength of the agglomerates.
3. The analysis of FTIR spectra confirmed the sensitivity of the $900-1200 \mathrm{~cm}^{-1}$ region to the water content of the material, which was observed in the form of numerous shifts and changes in the intensity of the peaks. It was shown that caking also affects the crystalline fractions of potato starch and wheat flour.

4. The growth of fungi can have an influence over the loss of starch strength, as well as decreasing its degree of crystallinity.

This work draws attention to the influence of moulds in the caking process and to changes in the behaviour of potato starch and wheat flour during the formation of agglomerates. Another issue worth pursuing in future research should be a better understanding of the mechanisms responsible for caking and its assessment under controlled conditions similar to those prevailing in warehouses and an investigation of the conditions that prevent the development of microbes. It is suggested that the study should take place over a longer time period in order to more thoroughly evaluate caking phenomena.

Conflict of interest: The Authors do not declare conflict of interest.

\section{REFERENCES}

Abdullah N., Nawawi A., and Othman I., 2000. Fungal spoilage of starch-based foods in relation to its water activity (aw). J. Stored Prod. Res., 36, 47-54. https://doi.org/10.1016/s0022-474x(99)00026-0

Alvani K., Qi X., Tester R.F., and Snape C.E., 2018. Physicochemical properties of potato starches. Food Chemistry, 125, 958-965. https://doi.org/10.1016/j.foodchem.2010.09.088

Arifin R., Dewanti-Hariyadi R., Hariyadi P., and Fardiaz D., 2014. Profile of microorganisms and amylose content of white corn flours of two local varieties as affected by fermentation process. 2nd Int. Conf. Food and Agricultural Sciences, IPCBEE, November 12-14, Auckland, New Zealand, 77, 13. https://doi.org/10.4236/fns.2014.521215

Bashir K. and Aggarwal M., 2017. Physicochemical, thermal and functional properties of gamma irradiated chickpea starch. Int. J. Biol. Macromol., 97, 426-433. https://doi.org/10.1016/j.ijbiomac.2017.01.025

Berghofer L.K., Hocking A.D., Miskelly D., and Jansson E., 2003. Microbiology of wheat and flour milling in Australia. Int. J Food Microbiol., 85, 137-149. https://doi.org/10.1016/s0168-1605(02)00507-x

Bröckel U., Whal M., Kirsch R., and Feise H.J., 2006. Formation and growth of crystal bridges in bulk solids. Chem. Eng. Technol., 29, 691-695. https://doi.org/10.1002/ceat.200600066

Buléon A., Colonna P., Planchot V., and Ball S., 1998. Starch granules: structure and biosynthesis. Int. J. Biol. Macromol., 23, 85-112. https://doi.org/10.1016/s0141-8130(98)00040-3

Carpin M., Bertelsen H., Bech J.K., Jeantet R., Risbo J., and Schuck P., 2016. Caking of lactose: A critical review. Trends Food Sci. Technol. 53, 1-12. https://doi.org/10.1016/j.tifs.2016.04.002 
Carr R.L., 1965. Classifying flow properties of solids. Chem. Eng., 72, 69-72.

Chen M., Wu S., Xu S., Yu B., Shilbayeh M., Liu Y., Zhu X., Wang J., and Gong J., 2018. Caking of crystals: Characterization, mechanisms and prevention. Powder Technol., 337, 51-67. https://doi.org/10.1016/j.powtec.2017.04.052

Chung M.S., Ruan R.R., Chen P., Chung S.H., Ahn T.H., and Lee K.H., 2000. Study of caking in powdered foods using nuclear magnetic resonance spectroscopy. J. Food Sci., 65, 134-138. https://doi.org/10.1111/j.1365-2621.2000.tb15968.x

Chung M.S., Ruan R., Chen P., Kim J.H., Ahn T.H., and Baik C.K., 2003. Predicting caking behaviors in powdered foods using a low-field nuclear magnetic resonance (NMR) technique. Lebensm. Wiss. Technol., 36, 751-761. https://doi.org/10.1016/s0023-6438(03)00096-3

Cuq B., Rondet E., and Abecassis J., 2011. Food powders engineering, between knowhow and science: Constraints, stakes and opportunities. Powder Technol., 208, 244-251. https://doi.org/10.1016/j.powtec.2010.08.012

Dankar I., Haddarah A., Omar F.E.L., Pujola M., and Sepulcre F., 2018. Characterization of food additive-potato starch complex by FTIR and X-ray diffraction. Food Chem., 260, 7-12. https://doi.org/10.1016/j.foodchem.2018.03.138

Dar M. Z., Deepika K., Jan K., Swer T. L., Kumar P., Verma R., Verma K., Prakash K., Jan S., and Bashir K., 2018. Modification of structure and physicochemical properties of buckwheat and oat starch by y-irradiation. Int. J. Biol. Macromol., 108, 1348-1356.

Descamps N., Palzer S., Roos Y.H., and Fitzpatrick J.J., 2013. Glass transition and flowability/caking behaviour of maltodextrin DE 21. J. Food Eng., 119, 809-813. https://doi.org/10.1016/j.jfoodeng.2013.06.045

Fitzpatrick J.J., Descamps N., O'Meara K., Jones C., Walsh D., and Spitere M., 2010. Comparing the caking behaviours of skim milk powder, amorphous maltodextrin and crystalline common salt. Powder Technol., 204, 131-137. https://doi.org/10.1016/j.powtec.2010.07.029

Fitzpatrick J.J., Descamps N., O'Meara K., O'Callaghan E., and O'Flynn J., 2008. A force-displacement tester for investigating the caking of powders. Proc. Int. Symp. Reliable Flow of Particulate Solids IV, June 10-12, Tromsø, Norway, RELPOWFLO IV, 600-605.

Fitzpatrick J.J., O'Connor J., Cudmore M., and Dos Santos D., 2017. Caking behaviour of food powder binary mixes containing sticky and non-sticky powders. J. Food Eng., 204, 73-79. https://doi.org/10.1016/j.jfoodeng.2017.02.021

Freeman T., Brockbank K., and Armstrong B., 2015. Measurement and quantification of caking in powders. Procedia Eng., 102, 35-44. https://doi.org/10.1016/j.proeng.2015.01.104

Guo P., Yu J., Copeland L., Wang S., and Wang S., 2018. Mechanisms of starch gelatinization during heating of wheat flour and its effect on in vitro starch digestibility. Food Hydrocolloids, 82, 370-378. https://doi.org/10.1016/j.foodhyd.2018.04.012

ISO 21527: 2009. Microbiology of food and animal feeding stuffs - Horizontal method for the enumeration of yeasts and moulds. Polish Committee for Standardization. https://doi.org/10.3403/bsiso21527
Mannaa M. and Kim K.D., 2017. Influence of temperature and water activity on deleterious fungi and mycotoxin production during grain storage. Mycobiology, 45(4), 240-254. https://doi.org/10.5941/myco.2017.45.4.240

Moorthy S.N., Andersson L., Eliasson A., Santacruz S., and Ruales J., 2006. Determination of Amylose content in different starches using modulated differential scanning calorimetry. Starch/Stärke, 58, 209-214. https://doi.org/10.1002/star.200500438

Nawrocka A., Krekora M., Niewiadomski Z., and Miś A., 2018. Characteristics of the chemical processes induced by cellulose in the model and gluten dough studied with application of FTIR spectroscopy. Food Hydrocolloids, 85, 176-184. https://doi.org/10.1016/j.foodhyd.2018.07.020

Nawrocka A., Miś A., and Niewiadomski Z., 2017. Dehydratation of gluten matrix as a result of dietary fibre addition A study on model flour with application of FT-IR spectroscopy. J. Cereal Sci., 74, 86-94. https://doi.org/10.1016/j.jcs.2017.02.001

Pereira A.P.M. and Sant'Ana A.S., 2018. Diversity and fate of spore forming bacteria in cocoa powder, milk powder, starch and sugar during processing: A review. Trends Food Sci. Technol., 76, 101-118. https://doi.org/10.1016/j.tifs.2018.04.005

Piecyk M. and Godlewska M., 2009. The effect of isolation and thermal treatment on the digestibility of the pea starch (in Polish). Nauka Przyr. Technol., 3, 4.

Sautour M., Soares Mansur C., Divies C., Bensoussan M., and Dantigny P., 2002. Comparison of the effects of temperature and water activity on growth rate of food spoilage moulds. J. Ind. Microbiol. Biotechnol., 28, 311-315.

https://doi.org/10.1038/sj.jim.7000248

Siemion P., Jabłońska J., Kapuśniak J., and Kozioł J.J., 2004. Solid state reactions of potato starch with urea and biuret. J. Polym. Environ. 12, 247-255. https://doi.org/10.1007/s10924-004-8152-2

Themeier H., Hollmann J., Neese U., and Lindhauer M.G., 2005. Structural and morphological factors influencing the quantification of resistant starch II in starches of different botanical origin. Carbohydrate Polymers, 71, 245-252. https://doi.org/10.1016/j.carbpol.2005.02.017

Wang S., Wang S., Guo P., Liu L., and Wang S., 2017. Multiscale structural changes of wheat and yam starches during cooking and their effect on in vitro enzymatic digestibility. J. Agric. Food Chem., 65(1), 156-166. https://doi.org/10.1021/acs.jafc.6b04272

Warren F.J., Gidley M.J., and Flanagan B.M., 2016. Infrared spectroscopy as a tool to characterize starch ordered structure - a joint FTIT-ATR, NMR, XRD and DSC study. Carbohydrate Polymers, 139, 35-42.

https://doi.org/10.1016/j.carbpol.2015.11.066

Zafar U., Vivacqua V., Calvert C., Ghadiri M., and Cleaver J.A.S., 2017. A review of bulk powder caking. Powder Technology, 313, 389-401. https://doi.org/10.1016/j. powtec.2017.02.024

Zhu F., 2018. Relationships between amylopectin internal molecular structure and physicochemical properties of starch. Trends Food Sci. Technol.,78, 234-242. https://doi.org/10.1016/j.tifs.2018.05.024 